\title{
Integrating photogrammetry and discrete fracture network modelling for improved conditional simulation of underground wedge stability
}

\author{
SF Rogers Golder Associates Ltd., Canada \\ RP Bewick Golder Associates Ltd., Canada
}

A Brzovic Codelco, Chile

D Gaudreau Golder Associates Pty Ltd, Australia

\begin{abstract}
Over the last decade, the advantages of discrete fracture network (DFN) models over more conventional tools for key block stability analysis have become increasingly apparent. Without their need for a series of simplifying assumptions regarding the fracture system, rock wedge formation and excavation geometry, DFN's ability to accurately capture the underground rock mass is clear. Coupled with the probabilistic consideration of block formation and joint strength parameters, they provide a valuable tool to the engineer for risk-based underground stability assessments.

However, recent changes in DFN technology have allowed a step change in modelling realism to be incorporated. A major improvement is the ability to generate DFN models directly conditioned to photogrammetric surveys so that the kinematic assessment is carried out on a structural description that accurately reflects the scanned location. This conditioned DFN model is embedded within an unconditioned stochastic description of the rock mass away from the scanned rock mass exposure, thus, providing a model that is constrained by the available geotechnical data (boreholes, scanning, trace mapping) but accurately conditioned to the key observed structures. The result is an ability to optimise excavation and ground support designs with a method that intelligently handles the natural heterogeneity imposed by the rock mass, combining what we see with what we know.
\end{abstract}

Keywords: discrete fracture network (DFN), kinematic stability, photogrammetry

\section{Introduction}

With improvements in technology such as borehole televiewers, optical borehole cameras, high resolution photography and laser scanning, coupled with modern image processing techniques, our ability to accurately describe the rock mass structure underground has increased. With ease, data can be acquired and processed that provides a detailed description of the underground rock mass along with key fracture parameters such as fracture length, orientation, intensity and aperture as well as some broad fracture surface parameters. Despite these improvements in rock mass characterisation, the standard of practice for tunnel kinematic assessments remains largely dependent on the rather conservative assumptions of rock wedges being defined by ubiquitous, infinitely continuous fracture planes. With the mining industry increasingly focussed on optimisation, there is a need to be better at matching our support designs to what is probably there rather than what is possibly there. One of the ways this has increasingly been achieved is through the application of discrete fracture network (DFN) modelling. DFN techniques recognise that the presence of fractures in the rock mass are spatially variable, with their geometric, mechanical and hydraulic parameters being more accurately described by statistical distributions. Thus, if we take the rich data from these modern imaging and characterisation systems, DFN models can be developed to provide a more robust, probabilistic approach to evaluating underground wedge stability and ground support requirements. However, until recently, the 
majority of DFN approaches utilised unconditional simulation, where the fracture model represented the global fracture population but did not exactly represent the structures observed intersecting the excavation. Recent advances in DFN modelling can now be used for conditional simulation of wedge stability based upon DFN models that both match the global fracture population as well as the observed fractures within the drift.

This paper describes the background to DFN-based wedge stability assessment as well as developments that allow conditional simulations to be carried out. A field example from the El Teniente mine is presented and illustrates the importance of this switch to conditional simulation.

\section{Discrete fracture network technology}

\section{$2.1 \quad$ Introduction}

Over the last decade or so, there has been increasing interest in the application of DFN technology to a wide range of mining applications. From wedge assessment (Rogers et al. 2006; Elmouttie et al. 2010; Grenon \& Hadjigeorgiou 2003; Grenon et al. 2015; Merrien-Soukatchoff et al. 2012), fragmentation assessment (Rogers et al. 2010), rock mass characterisation (Elmo et al. 2014), to mine water inflow management (Rogers et al. 2009) and synthetic rock mass modelling (Ivars et al. 2007), DFN modelling has increasingly demonstrated its advantages over more conventional approaches. The advantage of a DFN model is that it is better at describing local-scale problems because of its ability to capture the discrete fracture parameters more accurately than larger-scale continuum approaches. A discrete modelling approach captures the heterogeneity of the fracture system by explicitly describing key elements of the system and by defining fracture parameters (e.g. fracture size, orientation and intensity) stochastically and deterministically (where larger features are explicitly known to be present). DFN models can be readily built and, using Monte Carlo techniques, sampled many times in order to help constrain the likelihood of a particular outcome. Most importantly, they provide a clear and reproducible route, from site investigation data to modelling, because real fracture parameters are being preserved throughout the modelling process with limited approximation and judgement.

Whilst initially DFN models were geometrically simple, with fractures independently generated within simple volumes, they can now capture far more complex fracture systems, such as those that are more of an organised fracture system as encountered in coal measure sequences or other bedded units. Additionally, with more complicated geo-cellular modelling approaches, the fracture geometries can spatially vary across the model, resulting in models with spatially controlled orientations, intensities and other geometries and properties (Figure 1).
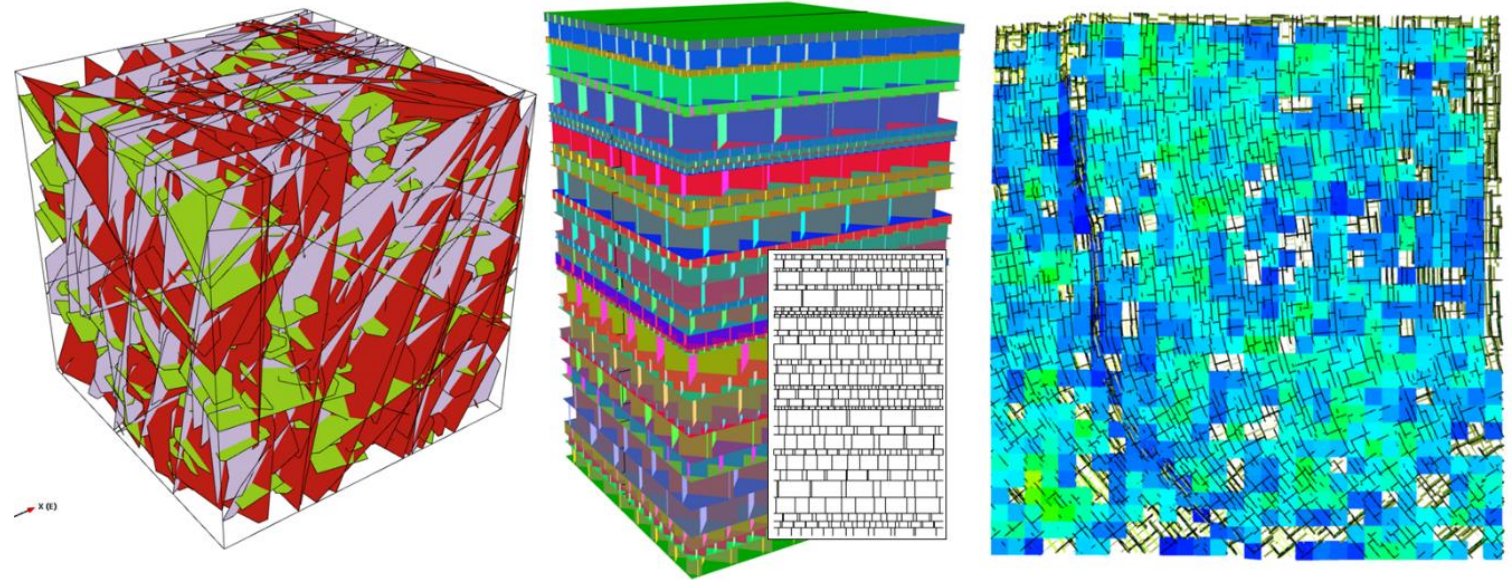

Figure 1 Examples of different DFN models: (left) conventional DFN model with a uniform spatial distribution, layered joint system from a quartzite rock mass; (centre) with a trace map through the model that shows the high degree of spatial ordering present within the fracture system; and, (right) a spatially variable model with varying orientation and intensity across the model (after Rogers \& Booth 2014) 


\subsection{Derivation of DFN parameters}

Basic DFN modelling requires a number of fracture parameters to be defined (Table 1). The primary parameters are required for all modelling as these represent the geometry of the fracture network. However the secondary parameters may also be defined depending on whether the application of the DFN model is hydraulic or geomechanical.

Table 1 Primary and secondary parameters for defining a DFN model (after Rogers \& Booth 2014)

\begin{tabular}{|c|c|c|}
\hline & Fracture parameter & Typically sources of data \\
\hline \multirow[t]{4}{*}{ Primary } & Orientation distribution & $\begin{array}{l}\text { Orientated core logging, borehole image logs } \\
\text { and mapping }\end{array}$ \\
\hline & Fracture size distribution & Mapping, ideally at multiple scales \\
\hline & Fracture intensity distribution & $\begin{array}{l}\text { Orientated core logging, borehole image logs } \\
\text { and mapping }\end{array}$ \\
\hline & Spatial variation of fracture intensity & Analysis of borehole or mapping data \\
\hline \multirow[t]{6}{*}{ Secondary } & Termination percentage & Mapping \\
\hline & Aperture distribution & Logging, mapping and hydraulic testing \\
\hline & Fracture shear properties & Logging, mapping and shear testing \\
\hline & Fracture stiffness properties & Shear testing but most usually literature \\
\hline & Fracture transmissivity distribution & Packer testing \\
\hline & Storativity distribution & Packer testing, well testing \\
\hline
\end{tabular}

In order to build a volumetrically simple DFN model, only the primary parameters of orientation, fracture size, intensity and its local spatial variation are required to be defined.

Fracture orientation is typically defined from borehole imaging, trace mapping data or photogrammetry. Where fracture orientation data are highly systematic and organised into distinctive fracture sets, the statistical properties of these sets can be defined and used as a key stochastic input into the DFN model. Alternatively, when the data have a more dispersed orientation pattern that does not support this approach, the technique of 'bootstrapping' can be used. This is a statistical method based upon multiple random sampling with replacement from an original sample to create a pseudo-replicate sample of fracture orientations (Efron 1979). A degree of 'noise' is introduced to each sample so that the pseudo sample is slightly different, such that multiple realisations result in a similar but not unique orientation model.

Definition of fracture length or persistence typically comes from outcrop mapping or photogrammetry. Fracture lengths need to be converted to an equivalent fracture radius for inclusion within the DFN model, with the radius being described by a number of different statistical distribution, such as the log-normal or exponential distribution. It is often a critical input into the DFN model and a key parameter for sensitivity studies. It is important to understand that particularly in the underground mine environment, where exposure is limited, observed and actual size distributions may deviate. For instance, a power law size distribution, sampled on the limited exposure of a drift, will in fact be seen as a log-normal distribution (LaPointe et al. 1999).

The DFN community uses a unified system of fracture intensity measures that provide an easy framework to move between differing scales and dimensions (Dershowitz \& Herda 1992). This is summarised in Table 2. This helps overcome some of the ambiguity of differing fracture intensity and density measures that are often used. 
Table 2 The $\mathrm{P}_{\mathrm{ij}}$ system of fracture intensity (after Dershowitz \& Herda 1992)

\begin{tabular}{|c|c|c|c|c|c|c|}
\hline & & Dimension of $\mathrm{m}$ & surement & & & \\
\hline & & 0 & 1 & 2 & 3 & \\
\hline & 1D & $\begin{array}{l}\mathrm{P}_{10}\left(\mathrm{~m}^{-1}\right) \\
\text { No of fractures } \\
\text { per unit length } \\
\text { of borehole }\end{array}$ & $\begin{array}{l}\mathrm{P}_{11} \\
\text { Length of } \\
\text { fractures per } \\
\text { unit length }\end{array}$ & & & $\begin{array}{l}\text { Linear } \\
\text { measured } \\
\text { (BHs, } \\
\text { scanline) }\end{array}$ \\
\hline $\begin{array}{l}\bar{E} \\
\bar{N} \\
4 \\
\overline{0} \\
c \\
\frac{0}{n} \\
\bar{c} \\
\bar{d}\end{array}$ & $2 \mathrm{D}$ & $\begin{array}{l}P_{20} \\
\text { No of fractures } \\
\text { per unit area }\end{array}$ & $\begin{array}{l}\mathrm{P}_{21}\left(\mathrm{~m}^{-1}\right) \\
\text { Length of } \\
\text { fractures per } \\
\text { unit area }\end{array}$ & $\begin{array}{l}\mathrm{P}_{22} \\
\text { Area of } \\
\text { fractures per } \\
\text { area }\end{array}$ & & $\begin{array}{l}\text { Areal } \\
\text { measures } \\
\text { (maps, drift } \\
\text { walls, bench } \\
\text { faces, etc.) }\end{array}$ \\
\hline$\overline{0}$ & $3 D$ & $\begin{array}{l}P_{30} \\
\text { No of fractures } \\
\text { per unit volume }\end{array}$ & & $\begin{array}{l}P_{32}\left(m^{-1}\right) \\
\text { Area of } \\
\text { fractures per } \\
\text { unit volume }\end{array}$ & $\begin{array}{l}\mathrm{P}_{33} \\
\text { Volume of } \\
\text { fractures per } \\
\text { unit volume }\end{array}$ & $\begin{array}{l}\text { Volumetric } \\
\text { measures }\end{array}$ \\
\hline Ter & & Density & & Intensity & Porosity & \\
\hline
\end{tabular}

Fracture intensity is typically derived either from borehole data (fracture logging or borehole imaging tools) or from trace mapping or photogrammetric imaging of exposed drift walls and back. Care needs to be taken in the use of these data as it can be highly directionally biased. The preferred measure of fracture intensity for a DFN model is known as $P_{32}$ (fracture area/unit volume), which is an intrinsic rock mass property. Whilst it cannot be directly measured it can be calculated from the 1D and 2D data, in Table 2, using an analytical solution (Wang 2006). Through this method, a relationship can be developed between observed fracture intensity and its associated $P_{32}$ that allows the volume of the model to be populated with the appropriate fracture intensity.

Once all parameters and properties of the fracture system have been defined, the next step is the construction of an appropriate DFN model. This should be generated using an appropriate site geological and geometrical model and, where possible, conditioned to borehole and trace map data. The DFN model should include large deterministic features, such as stratigraphic contacts, faults and fracture zones, and can be generated within simple geometric volumes, complex grids or stratigraphic zones.

\subsection{Photogrammetry constrained DFN assessment}

One of the criticisms of the stochastic modelling approach is that it captures the global fracture parameters of a domain but not the actual specific pattern at an actual location. This is an unfair criticism if the assessment is aimed at quantifying the likely nature of unstable blocks in a particular domain or evaluating the likely frequency of unstable blocks over a certain distance. However, if the assessment itself is site specific, then ensuring that the modelled free face matches the observed fracture pattern whilst allowing the unseen rock mass to be populated by a stochastic fracture pattern provides a more rigorous solution. The workflow that we use is shown in Figure 2 and subsequently described. 


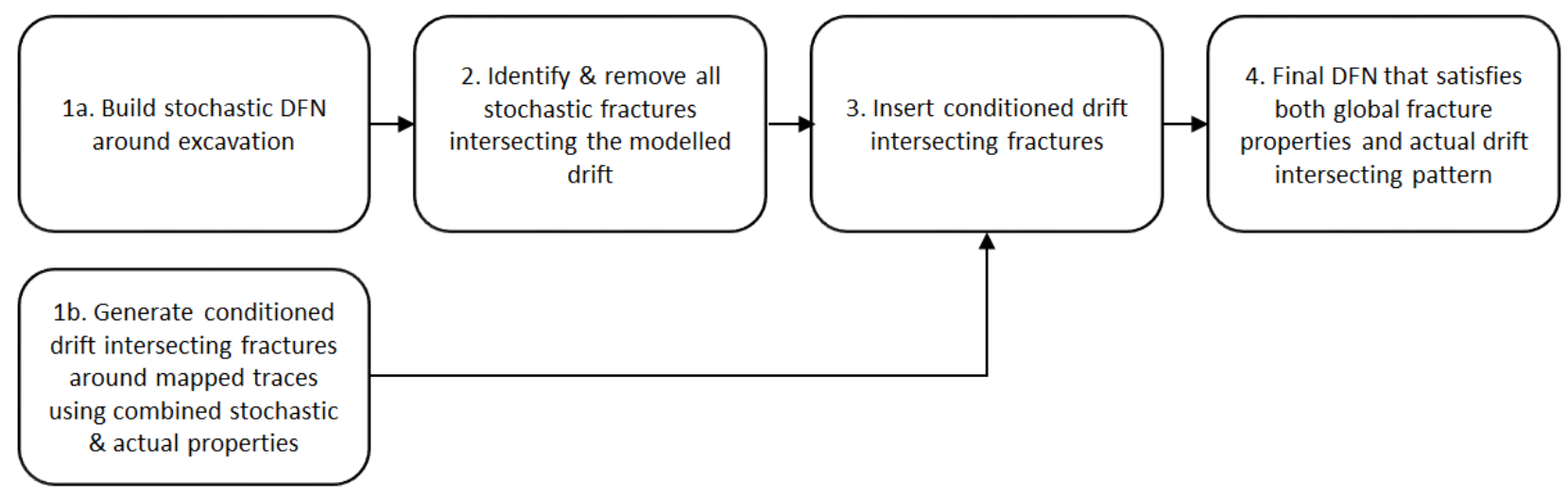

Figure 2 Workflow for the generation of a DFN model conditioned to actual mapping data

To illustrate this, an example from the El Teniente mine is presented where the approach has been used to build a fully conditional DFN around part of a drift experiencing significant structurally controlled overbreak. Photogrammetry of the drift was carried out with a scan of the drift and associated overbreak, shown in Figure 3. This figure also shows some of the structures interpreted, fitted as planes to the interpreted fractures.
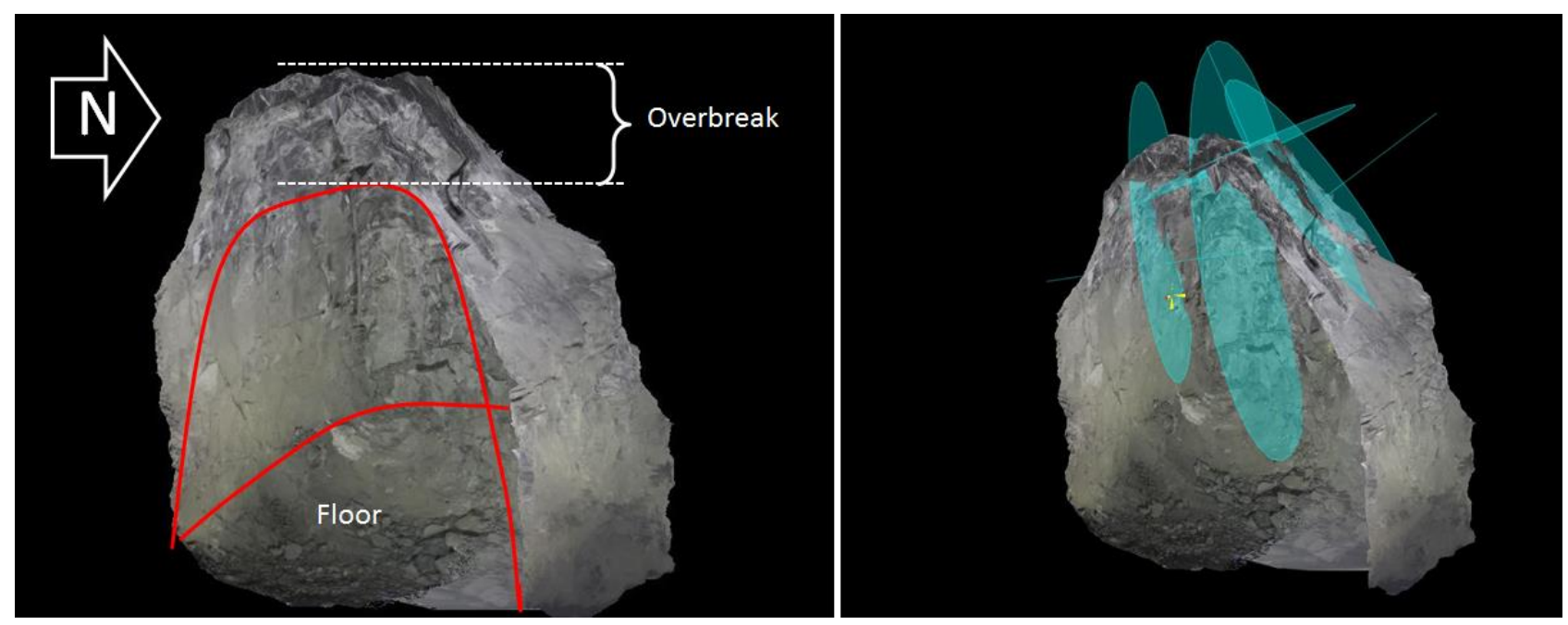

Figure 3 Photogrammetric image of: (left) overbreak in a drift; and, (right) with some of the interpreted fractures shown

The first step in the process of generating a conditional DFN simulation is to convert the photogrammetric interpretation into a local DFN model. An important point for consideration is that the mapped fracture planes do not represent fully deterministic features. They simply represent fractures of known orientation, a known trace location and trace length but an unknown fracture radius (i.e. the extent to which the fractures extend away into space). Thus, these observed fracture trace lengths need to be converted into an underlying fracture radius distribution using the analytical approach of Zhang et al. (2002) (Figure 4). 

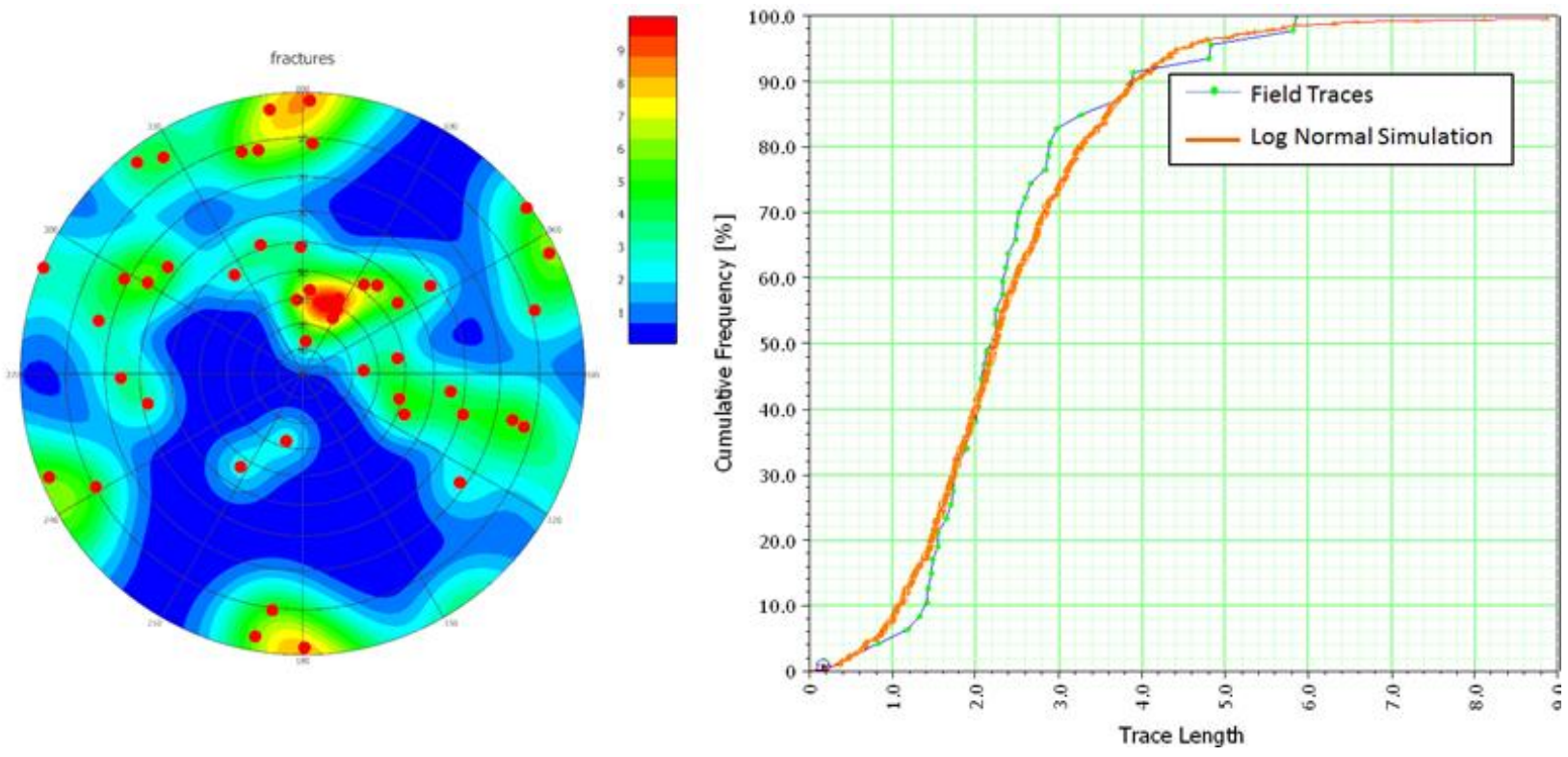

Figure 4 Two different sets of data obtained from the photogrammetry survey: (left) measured fracture orientations from the survey; and, (right) distribution of observed fracture traces and the best fit log-normal model of fracture traces derived from an underlying fracture radius distribution

Once the fracture radius distribution has been derived, fractures can be generated around the fracture traces that honour the trace location, the underlying fracture radius distribution and the actual orientation. It is important to understand that the traces mapped in the survey conceptually represent a chord to a disc and so, despite the fact that they are a hard measurement, their application to constraining fracture size is non-unique. Therefore, multiple realisations of fractures that have the observed orientation, the same trace intersection on the drift but different actual fracture radii, can be generated. Figure 5 shows the mapped traces on the drift shell and one realisation of fractures generated around those traces.

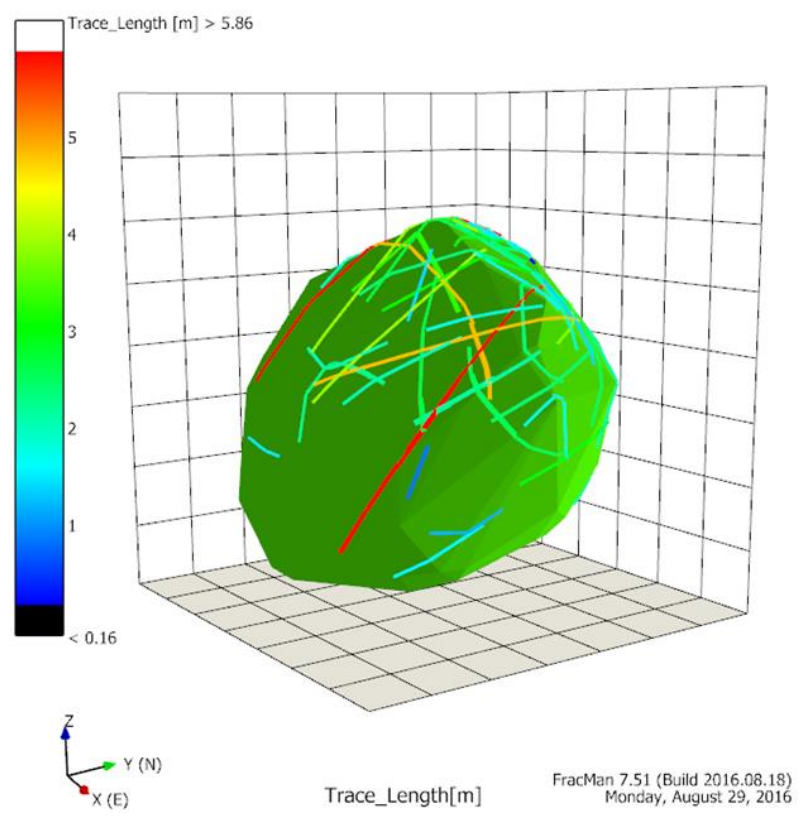

(a)

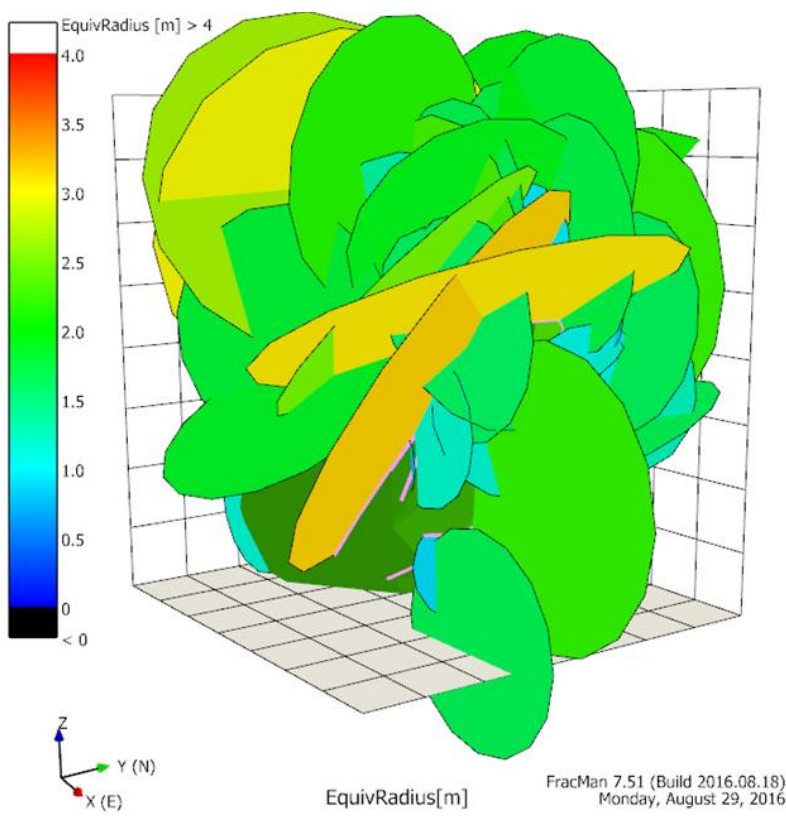

(b)

Figure 5 (a) Drift shell with observed traces (coloured by length); and, (b) stochastic fractures conditioned to the observed fracture traces (coloured by radius) 
The next step is the generation of the unconditioned stochastic DFN model around the excavation. Using the regular approaches for defining stochastic properties, as laid out in Section 3, a conventional model is readily generated. Orientation can be constrained solely from features identified on the photogrammetry survey or they can supplemented by other mapping or borehole data. In this case, the stereonet in Figure 4 is used. The fracture radius distribution is the same as the one used for the trace map fractures previously described.

However, deriving fracture intensity from the photogrammetric survey is slightly less straightforward than normal as the measured data are in $P_{21}$ format and need to be converted to $P_{32}$ (Table 2). In order to define $P_{32}$ from $P_{21}$ measurements, we need define the coefficient $C_{23}$ as follows:

$$
P_{32}=P_{21} \times C_{23}
$$

where:

$\mathrm{C}_{23}$ is the geometric conversion coefficient from 2D to 3D and is a function of the drift shell geometry and the orientation distribution of the fractures.

Practically, this is achieved by generating a stochastic DFN model in a modelling volume surrounding the tunnel shell, using the fracture radius distribution and orientation distribution previously described and an arbitrarily high $P_{32}$ intensity ( $P_{32}$ simulation). The high arbitrary $P_{32}$ value is used, as it results in a better estimate of $\mathrm{C}_{23}$. Once the DFN model is generated, the fractures are sampled onto the drift shell to make a simulated trace map and the resultant $P_{21}$ is determined ( $P_{21}$ Simulation). From Equation (1), the model can then be regenerated at the correct intensity using the relationship:

$$
\mathrm{P}_{32 \text { [ACtual] }}=\mathrm{P}_{32 \text { [SImUlation] }} / \mathrm{P}_{21 \text { [SImUlation] }} \times \mathrm{P}_{21 \text { [Actual] }}
$$

Having calculated the required $P_{32}$, the stochastic DFN model can be regenerated within the modelling volume, using the same fracture radius distribution and orientation distribution described previously and the calculated $\mathrm{P}_{32}$ intensity (Figure 6).

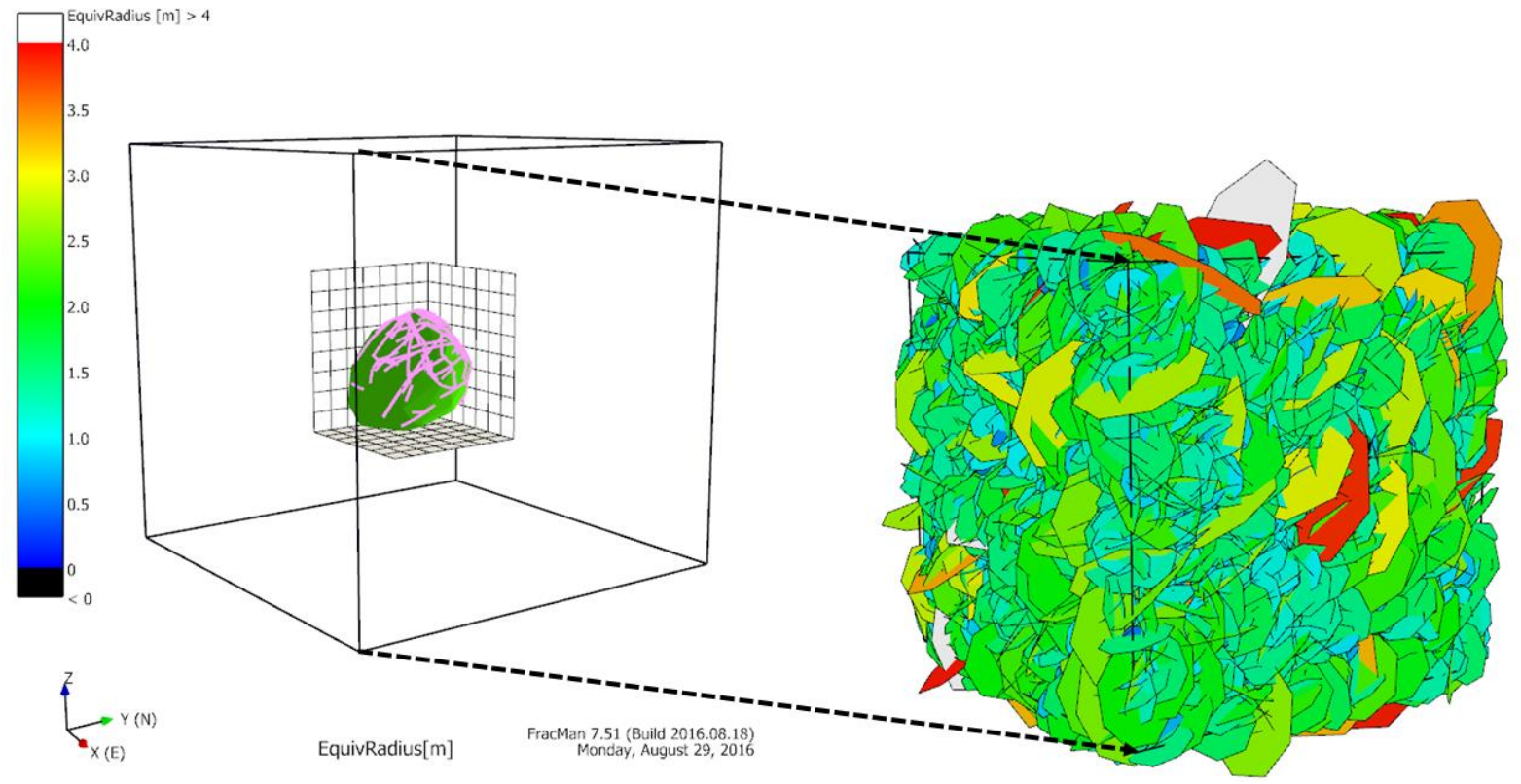

Figure 6 Generation of the stochastic fractures in the volume surrounding the drift and trace map fractures (fractures coloured by radius)

The DFN model shown in Figure 6 honours the global fracture statistics but our ultimate goal is a conditional simulation that actually matches what was observed on the drift walls. Thus, the fractures from the global stochastic model that actually intersect the drift shell need to be removed and be replaced with the conditioned fractures generated from the interpreted traces, resulting in a model that now honours both the global fracture population and the local drift intersecting population. This is achieved by flagging fractures that intersect the drift shell and then deleting them from the model and inserting the trace map fractures (Figure 7). 


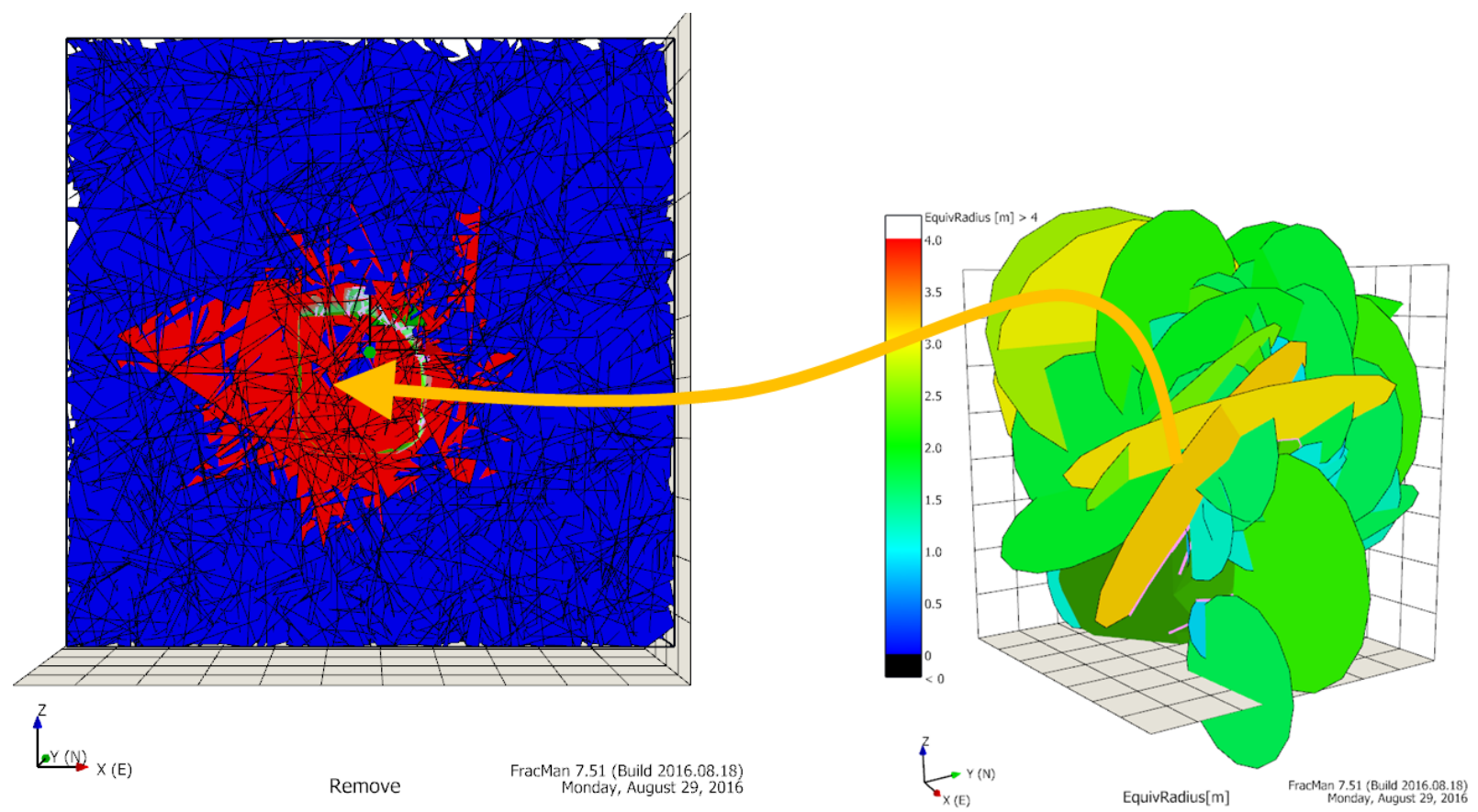

Figure 7 Section through the DFN model showing the stochastic fracture set (blue) with fractures intersecting the drift in red. To generate the conditioned model, the red fractures are deleted and the trace fracture set inserted in its place resulting in a fracture population that satisfies both the global and local fracture properties

\section{Conventional and discrete fracture network-based kinematic stability assessment}

\subsection{Conventional wedge assessment}

The key to underground wedge assessment is understanding the 3D size and interlocking nature of rock blocks (Hatzor \& Goodman 1992). The primary key-block algorithms currently available are well documented (Einstein \& Glynn 1979; Goodman \& Shi 1985; Carvalho et al. 1991), with the assessment of wedge stability in both underground excavation and slope applications typically using the same basic limit equilibrium approach (Goodman \& Shi 1985). The algorithm is fairly simple and has been implemented in a number of software packages, e.g. Unwedge (Carvalho et al. 1991), each with its own advantages and limitations.

One of the limitations of the conventional approach is that wedges are formed by discrete planes (typically only three fractures), each of which is considered ubiquitous and typically infinite in length (with some constraint). Thus, the maximum possible wedge is defined around the excavation. This does not allow for the consideration of more complex block geometries, variable fracture lengths, the influence of rock bridges, or for the scatter in the actual field fracture orientations. The assessment can, therefore, become rather subjective as engineering judgment is used to identify structures that will form the wedges. Thus, there is convoluted workflow from detailed data acquisition, through processing of data, assumptions and assessment that results in the estimation of the possibility of wedges forming around the excavation. That is possibility, not probability. To really optimise tunnel support, there is a need to be able to determine the probability of wedge formation and, therefore, the likelihood of the occurrence of a certain size wedge as a function of distance driven. This is the value of the DFN approach (Rogers et al. 2006). 


\subsection{DFN assessment for tunnel stability}

When evaluating kinematic block stability using a DFN approach, the assessment is carried out using the modelled fracture network with its fully defined spatial and geometrical properties (Dershowitz \& Carvalho 1996). This is in contrast to the conventional method with its assumption of fracture ubiquity. Thus, the DFN approach considers the 'probability' of adverse block formation rather than simply considering the 'possibility' of wedge formation.

The first stage of the stability assessment is the identification of 3D rock blocks in the DFN models that have at least one face in common with the tunnel being evaluated. To achieve this, a trace map for the fracture intersections with the tunnel is generated. Once the tunnel trace map has been created, rock blocks can be constructed by identifying those fractures that form closed 2D blocks in the trace map, forming trace maps on those fractures and repeating the process until fractures participating in trace maps have trace maps of their own (Dershowitz \& Carvalho 1996) (Figure 8).

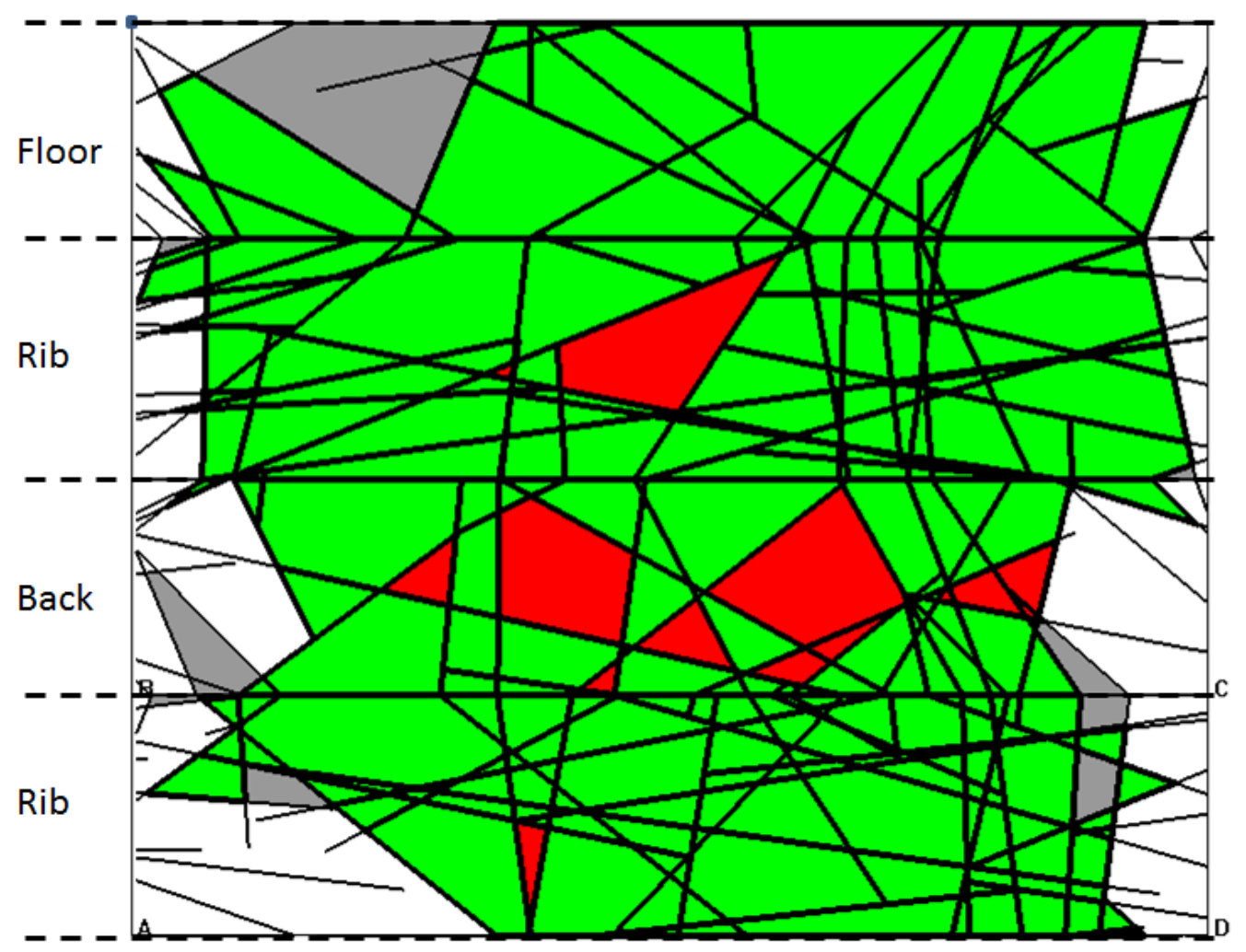

Figure 8 Simple example of a developed section (unwrapped drift model) around a square section drift showing how blocks are identified first in $2 \mathrm{D}$ as closed polygons and then each $2 \mathrm{D}$ polygon is searched into the rock mass to see if it forms a 3D block. These blocks are then tested for stability with stable blocks coloured green and unstable blocks (Factor of Safety $<1$ ) coloured red

This results in a collection of faces and connection information. All of the faces are processed using an unfolding algorithm to generate the minimum volume polyhedron that connects to a tunnel face. The rock block volume is computed by a process of 3D tessellation with the associated block mass being calculated using this computed volume and the assigned rock density.

The stability assessment for rock blocks and wedges defined by realistic fracture geometries from a DFN model is functionally identical to the conventional wedge analysis. The fundamental difference is that the assessment is carried out on actual defined 3D blocks for a specific realisation of the fracture geometry, rather than on a combinatorial approach of infinite fractures. The stability assessment is carried out by checking whether each identified block satisfies the criteria for unconditional stability, whether the block may slide (along one or two sides), or whether it is a free falling block. The Factor of Safety (FS) is then 
calculated based on limit equilibrium assumptions. For the purposes of this work, the focus is more on the general size of rock blocks in general rather than whether they are stable or unstable. As such, of interest are more how and where blocks are formed, rather than their stability. Thus, red and green blocks can be considered as equal for now.

\subsection{Comparison between unconditioned and conditioned DFN wedge assessment}

In order to give more insight into the impacts of using a conditional DFN model over a purely stochastic model, a comparison between the two approaches has been undertaken. The DFN model described previously was used and the kinematic stability in the original, 'as built' back of the drift evaluated using the FracMan ${ }^{\circledR}$ code (Dershowitz et al. 1995). The stochastic model (using a Baecher spatial distribution) honours the global statistical properties of the fracture system, whereas the conditional model honours both the global statistical properties and the local fracture properties at the drift back. It should be reiterated that the fractures, as mapped at the drift, are only semi-deterministic. The orientation and the location are known, but we do not actually know the size of the structures. We can derive the size distribution of those features but can never be sure exactly how far an individual fracture extends away from the excavation. To address this issue, there are two broad approaches that can be followed. One is to build multiple realisations of the DFN models, where both the background stochastic and conditioned stochastic components of the DFN model are regenerated each time. Alternatively, a sensitivity approach can be used to test critical inputs (in this case the size distribution) and evaluate the impact on the results. Shown in Figure 9 are images from the global stochastic model, the conditional model and a conditional model where the fracture size distribution was increased (the mean size was doubled).
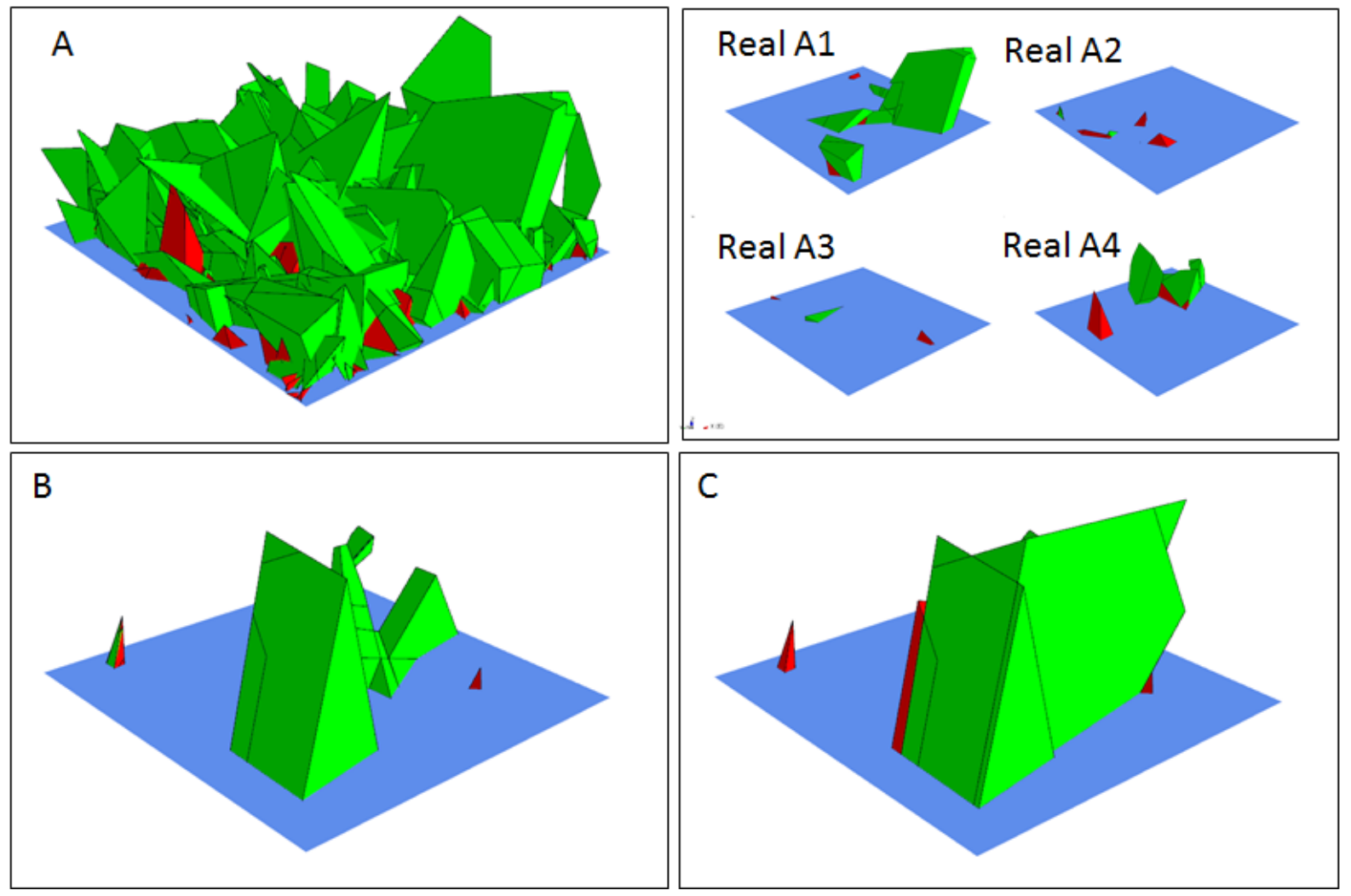

Figure 9 Rock blocks formed above the back of a drift $(4.0 \times 4.6 \mathrm{~m})$ in area: (a) stochastic model conditioned to the global fracture population; (b) stochastic model conditioned to both global and local (drift intersecting) fracture populations; and, (c) is the same as (b) but with fractures using a larger size distribution. All three models show the results of 50 iterations. Top right shows four different individual realisations from Model $A$, the global stochastic model. Red blocks are unstable $(\mathrm{FS}<1)$ and green are stable (FS $>1)$ 
Examination of the results in Model $A$ and $B$ show some striking differences. With the purely global stochastic model, the blocks that are forming (whether stable or unstable) are seen to be distributed across the entire drift back. With no underlying spatial model other than the Poisson process for generating fracture centres, the probability of block occurrence is equal across the free face. This is in contrast to Model B where the conditioning of the model to actual drift intersecting fractures ensures that the blocks that do form, do so in a very limited area. As can be seen, the 50 stochastic realisations fill the entire free face whereas the 50 conditioned simulations generate largely on top of each other. The second big difference between the two models is that the average blocks are bigger in the conditioned stochastic case. Model B shows a much smaller number of larger blocks and this is borne out when the apex height of all blocks are examined. This shows the median height in the conditioned model is approximately double what is observed in the stochastic model, Figure 10. Note also that in Figure 9(c), the conditioned model with larger fractures does not result in a taller wedge, however, it does create additional large volume wedges as a result of the increased fracture area. Knowing the exact size of fractures mapped at the drift and how they extend away into the rock mass, is always going to remain a critical uncertainty. This means carrying out sensitivities on this critical parameter is imperative.
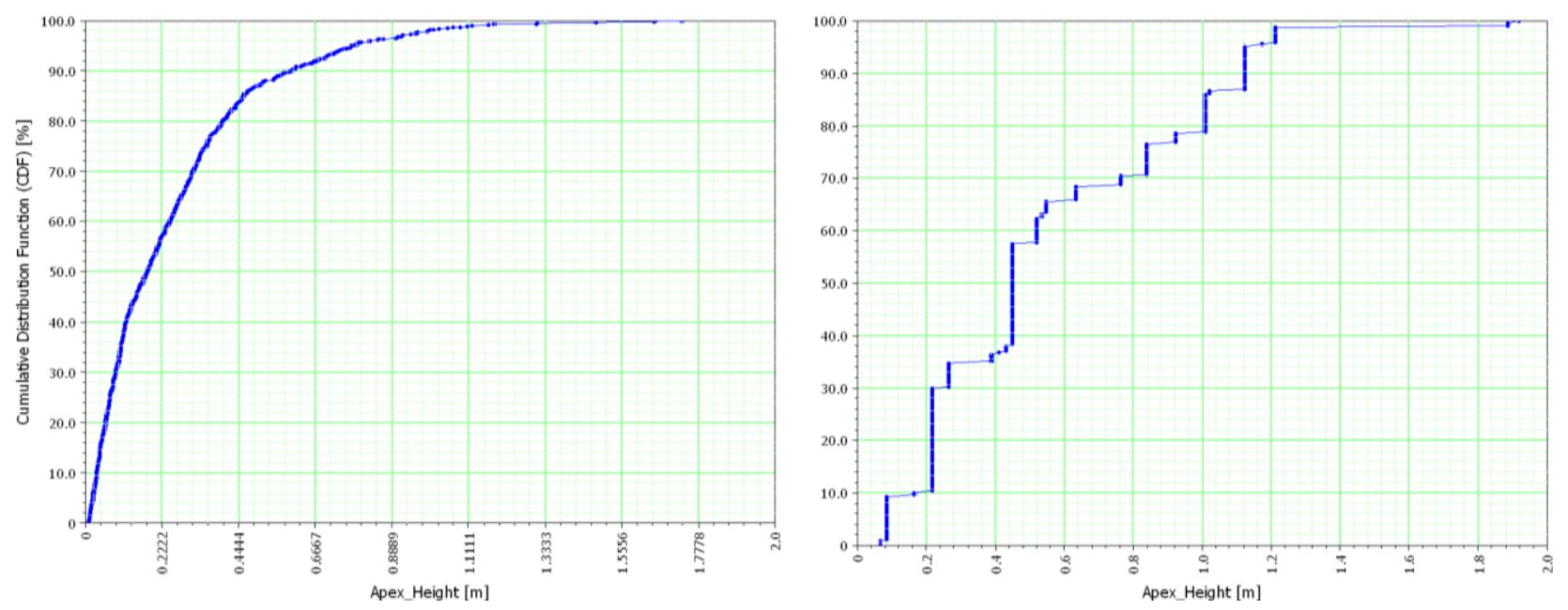

Figure 10 Distribution of apex height for the: (left) stochastic model A; and, (right) the conditioned model B

One issue that has not been fully addressed is the fact that in generating the conditioned model, the underlying Poisson distribution of the global population has been disturbed. Further testing is required to establish how best to minimise any impact this might make on the outcome of the model.

The real value of the DFN modelling is that once the size and shape of blocks has been determined, support patterns can be designed that actually fit reality. The upside is a more focussed ground support system that is designed for what is present rather than simply what might be. The actual operational application of the conditioned DFN approach will be the focus of an ongoing study, as the authors seek to find the best way to exploit this innovative approach.

\section{$4 \quad$ Concluding remarks}

Evaluating kinematic tunnel stability remains a critical task in underground operations. As the industry increasingly moves to a risk-based approach, there is a need for more accurate rock mass characterisation that feeds directly into the ultimate assessment approach. A clear advantage of the DFN approach, over more conventional methods, is that it results in a more accurate representation of the $3 \mathrm{D}$ fracture network geometry, which itself can be fed directly into the kinematic assessment without generalisation or reduction. This probabilistic approach, using measured fracture size and orientation data, effectively allows the engineer to apply an appropriate level of conservatism to the design application. The assessment also allows the engineer to optimise bolt sizes, lengths and orientations to provide the most effective support system to meet a given design criteria. 
Photogrammetry is seen as a complimentary technology to DFN modelling because it can provide the large, statistically significant, spatially located geotechnical data sets required to produce the most robust results. In addition to the generation of large data volumes, it is the increasing ability to generate DFN models conditioned to the actual fracture observations that makes them an increasingly accountable and attractive modelling methodology for a variety of geotechnical and geomechanical assessments. The ability to generate DFN models directly conditioned to photogrammetric surveys so that that the kinematic analysis is carried out on a structural description that accurately reflects the scanned location provides a significant step forward in modelling capability. The result is an ability to optimise excavation and ground support designs with a method that intelligently handles the natural heterogeneity imposed by the rock mass, combining what we see with what we know.

\section{References}

Carvalho, J, Hoek, E \& Lee, B 1991, UnWedge: Underground Wedge Analysis, Department of Civil Engineering, University of Toronto, Toronto.

Dershowitz, W \& Carvalho, J 1996, 'Key-block tunnel stability analysis using realistic fracture patterns in rock mechanics tools and techniques', in M Aubertin (ed.), Proceedings of the 2nd North American Rock Mechanics Symposium: NARMS '96, AA Balkema, Rotterdam, pp. 1747-1751.

Dershowitz, W, Lee, G, Geier, J, Foxford, T, LaPointe, P \& Thomas, A 1995, FracMan Interactive Discrete Fracture Data Analysis, Geometric Modeling, and Exploration Simulation, User Documentation, version 2.5, report 923-1089, Golder Associates Inc, Seattle.

Dershowitz, W, \& Herda, H 1992, 'Interpretation of fracture spacing and intensity', in JR Tillerson \& W Wawersik (eds), Proceedings of the 33rd U.S. Rock Mechanics Symposium, Balkema, Rotterdam, pp. 757-766.

Efron, B 1979, 'Bootstrap methods: Another look at the jackknife', The Annals of Statistics, vol. 7, no. 1, pp. 1-26.

Einstein, H \& Glynn, E 1979, 'Probability of kinematic instability in rock slopes: A numerical approach', Proceedings of the 20th US Symposium on Rock Mechanics, American Society of Civil Engineers, New York, pp. 317-325.

Elmo, D, Rogers, S, Stead, D \& Eberhardt, E 2014, 'Discrete fracture network approach to characterise rock mass fragmentation and implications for geomechanical upscaling', Mining Technology, vol. 123, no. 3, pp. 149-161.

Elmouttie, M, Poropat, G, \& Krähenbühl, G 2010, 'Polyhedral modelling of underground excavations', Computers and Geotechnics, vol. 37, no. 4, pp. 529-535.

Goodman, R, \& Shi, G 1985, Block Theory and Its Application to Rock Engineering, Prentice Hall, New York.

Grenon, M \& Hadjigeorgiou, J 2003, 'Drift reinforcement design based on discontinuity network modelling', International Journal of Rock Mechanics and Mining Sciences, vol. 40, no. 6, pp. 833-845.

Grenon, M, Landry, A, Hadjigeorgiou J \& Lajoie, P 2015, 'Contribution to drift design using discrete fracture network modelling at the Éléonore mine in Canada', in Y Potvin (ed.), Proceedings of the International Seminar on Design Methods in Underground Mining, Australian Centre for Geomechanics, Perth, pp. 339-351.

Hatzor, Y \& Goodman, R 1992, 'Application of block theory and the critical key block concept to tunneling: Two case histories', Proceedings of the Conference on Fractured and Jointed Rock Masses, International Society for Rock Mechanics, Lisboa.

Ivars, D, Deisman, N, Pierce, M \& Fairhurst, C 2007, 'The synthetic rock mass approach-A step forward in the characterization of jointed rock masses', Proceedings of the 11th International Congress On Rock Mechanics, International Society for Rock Mechanics, Lisboa.

LaPointe, P, Cladouhos, T \& Folin, S 1999, Calculation of displacements on fractures intersecting canisters induced by earthquakes: Aberg, Beberg and Ceberg examples, technical report, TR-99-03, SKB.

Merrien-Soukatchoff, V, Korini, T \& Thoraval, A 2012, 'Use of an integrated discrete fracture network code for stochastic stability analyses of fractured rock masses', Rock Mechanics and Rock Engineering, vol. 45, no. 2, pp. 159-181.

Rogers, S \& Booth, P 2014, 'Integrated photogrammetry and DFN modelling for improved rock mass characterisation and engineering design', Proceedings of the 15th Australasian Tunnelling Conference 2014, The Australasian Institute of Mining and Metallurgy, Carlton South, pp. 203-208.

Rogers, S, Chorley, D, Pesendorfer, M, Zawadski, W \& Greer, S 2009, 'Hydrogeological characterisation \& conceptual DFN flow modelling of slope pressures within the Diavik diamond mine, NWT', in J Read (ed.), Proceedings of the International Symposium on Rock Slope Stability in Open Pit Mining and Civil Engineering, University of the Andes, Santiago.

Rogers, S, Elmo, D, Webb, G \& Catalan, A 2010, 'A discrete fracture network based approach to defining in situ, primary and secondary fragmentation distributions for the Cadia East panel cave project', in Y Potvin (ed.), Proceedings of the Second International Symposium on Block and Sublevel Caving, Australian Centre for Geomechanics, Perth, pp. 425-440.

Rogers, S, Moffitt, K \& Kennard, D 2006, 'Probabilistic tunnel and slope block stability using realistic fracture network models', in DP Yale (ed.), Proceedings of the 41st US Rock Mechanics Symposium, American Rock Mechanics Association, Alexandria.

Wang, X 2006, Stereological Interpretation of Rock Fracture Traces on Borehole Walls and Other Cylindrical Surfaces, PhD thesis, Virginia Polytechnic Institute and State University, Blacksburg.

Zhang, L, Einstein, H \& Dershowitz, W 2002, 'Stereological relationship between trace length and size distribution of elliptical discontinuities', Géotechnique, vol. 52, no. 6, pp. 419-433. 